\title{
DESIGN, MODELING, AND IMPLEMENTATION OF PIC BASED ELECTRICAL WHEELCHAIR
}

\author{
Mohannad Abid Shehab Ahmed \\ Lecturer, Engineering College, Al-Mustansirya University \\ E-mail: engineer.moh72@gmail \\ (Received: 4/4/2013; Accepted: 5/1/2014)
}

\begin{abstract}
Nowadays, voice is one of the methods commonly used to control the electrical and electronic appliances because of easily being reproduced by human.

Many people with disabilities do not have the dexterity necessary to control a joystick on an electrical wheelchair, so the aim of this study is to control access to voice services and to implement a wheelchair using small vocabulary word recognition system.
\end{abstract}

The HM2007 IC serves as the ear that will listen and interpret the voice command, while the PIC18F458 serve as the brain of the system that will process and coordinate the correct output of the input command to control the wheelchair motors.

The methodology adopted is speech recognition development for isolated word from independent speakers where any speaker has two different sentences first for training and the second for testing to release the operation.

The input of the system is a set of pick up five words used to control the movements of two motors connected to PIC $18 \mathrm{~F} 458$ which is used as a programmable and controllable device, the speed of the motors is adjusted using the PWM (Pulse Width Modulation) technique where the duty cycle is simultaneously varied according to input switching device.

For more efficient design, the system can worked in worst condition that could be achieved in noisy environment with different signal to noise ratios, besides that the electric power supply can utilize the solar cells.

Finally, the proposed system is implemented and tested upon a data base consists of ten speakers (6 males and 4 females) and its performance rises the algorithm efficiency and reduce the execution time with $97 \%$ noiseless overall accuracy.

Keyword: HM2007, Solar cells, Darlington pair, PIC 18F458, Wheelchair, Speech Recognition, Micro C programming. 
1. OVERVIEW

Voice Recognition Embedded System would be an advanced control system that uses human voice/audio speech to identify the speech command. It has the following applications and advantages ${ }^{[1]}$ :

1. Support to disabled people.

2. Alerts/warning signals during emergencies in airplane, train and/or buses.

3. Development of educational games and smart toys.

4. Automatic payment and customer service support through telephones.

5. No key required for devices such as personal computer and laptops, automobiles, cell phones, door locks, smart card applications, ATM machines etc.

\section{OBJECTIVE OF PROJECT}

The main aim is to deploy wheelchair in different environments in order to assist and help human in different daily tasks like transportation of people (elderly or reduced mobility people), visiting different places, assists people to carry tools in friendly environment (home, hospital, ...).

The project will enable the users to control the electrical appliance in home and street using their voice as the medium that will control the power system. It also aims to allow not only the user that have train the system with their voice but it extend to the other users who also can use the system without do the training process again.

Besides that, the way for supplying power to wheelchair circuits and motors is enhanced using chargeable battery through solar cells.

The overall real design can be illustrated through figure (1).

\section{SCOPE OF PROJECT}

In order to achieve the objective of this project, there are several scope must be identified; a voice recognition circuit utilizing HM2007, follow by designing of the microcontroller board using PIC 18F458 as the hardware that control the movements in all directions, next a $\mathrm{C}$ microprogramming is to be written and coded to enable the microcontroller to be able to function properly as desired.

Our project can be summarized as the following phases:

\section{Phase 1 - Hardware Development Process}

\section{a. Solar Cell Charger}


The function of this charger is to cater for the other end with $12 \mathrm{v}$ using DC inverter, we are looking at charging a $12 \mathrm{v}$ battery, $1 \mathrm{Amp}-\mathrm{hr}(1 \mathrm{AHr})$ using the cheapest set of solar cells and a simple inverter. The circuit diagram is as shown in figure (2).

The circuit is a single transistor oscillator called a feedback oscillator, or more accurately a blocking oscillator. It has 15 turns on the primary and 45 turns on the feedback winding to produce a high voltage during part of the cycle, so this voltage is delivered to the output via a high-speed diode to produce the output. The output voltage consists of high voltage spikes, these spikes feed into the battery with prototype delivered $30 \mathrm{~mA}$ as a starting current and as the battery voltage increased, the charging current dropped to $22 \mathrm{~mA}$.

The transistor is turned on via the $1 \mathrm{ohm}$ base resistor causes current to flow in the primary winding and produces magnetic flux, this flux cuts the turns of the feedback winding and produces a voltage in the winding that turns the transistor ON more. The magnetic flux in the core of the transformer begins to collapse and this produces a voltage in the feedback winding that is opposite to the previous voltage. This has the effect of working against the 1 ohm resistor and turns off the transistor even more.

The voltage produced in the winding depends on the quality of the magnetic circuit and the speed at which it collapses.

The 220uf across the solar panel is designed to reduce the impedance of the panel so that the circuit can work as hard as possible.

The 10uf in the input works in a similar manner to $220 \mathrm{uf}$ so these two capacitors components improve the efficiency of the circuit considerably.

The BC 547 prevents the ZTX 851 oscillator transistor turning on when the voltage is slightly above $12 \mathrm{v}$. The $10 \mathrm{uf}$ on the output stores the reference voltage and keeps the BC 547 turned on during the time when the output voltage is above $12 \mathrm{v}$. This effectively stops the oscillator, but as soon as the output voltage drops below $12 \mathrm{v}$, the circuit comes back into operation, charge-pumping the $10 \mathrm{u}$ on the output.

The $12 \mathrm{v}$ zener works like this: No voltage appears on the anode end (the end connected to the $100 \mathrm{R}$ resistor) until $12 \mathrm{v}$ is on the cathode. Any voltage above $12 \mathrm{v}$ appears on the anode and this voltage passes through the 100R to the base of the BC 547.

\section{b. Voice Recognition}

A chip called HM2007 can convert the voice command into digital signal; it is a single CMOS voice recognition LSI circuit with on-chip analog front end, voice analysis, recognition process and system control functions ${ }^{[2]}$. 
The HM2007 is a 48 pin IC that, provides the front end voice recognition processing, and can operate in one of two modes: The stand alone mode uses just a simple keyboard and display, or the CPU mode where the chip is connected to a host PIC.

This chip also has a rather short response time which is less than 300 milliseconds. This chip has a set of inputs for the keypad that mainly used for the training purposes which located at the pin 4,5,6,8,9,10 and 11 ; this enables the chip to store the word train to the system. SA0 to SA12 is the external memory address bus while D0 to D7 is the external memory data bus. Last is the RDY pin at the pin number 7 that will serve as the indicator of the chip where it will be exert high signal if the chip is busy and it is an active-low output .

The chip provides the options of recognizing either 40 words each with a length of 0.96 second or 20 words each with a length of 1.92 second. It doesn't have an internal memory, that is why it should be connected to the external memory which is $8 \mathrm{k} \times 8$ SRAM memory with 13 address lines. There is a backup memory battery for the SRAM on the main board; this battery keeps the trained words safely stored in the SRAM when the main power is turned off. Due to the limited words needed to be stored and accessed, it will use the internal memory of the PIC $18 \mathrm{~F} 458$ itself instead of external $8 \mathrm{k} \times 8$ SRAM to support the operation of the HM2007.

The output of the chip (the data bus) is in BCD (binary coded decimal) which will be connected to the display circuit. The data buses are also connected to the interface of the microcontroller PIC 18F458 to respond to corresponding command.

The HM2007 speech recognition IC hardware circuit is that connect in figure (3).

The keypad and digital display are used to communicate and program the HM2007 chip, the keypad is made up of 12 normally open momentary contact switches. When the circuit is turned on, " 00 " is on the digital display, the red LED (READY) is lit and the circuit waits for a command.

Press " 1 " on the keypad (display will show "01" and the LED will turn off), then press the TRAIN key ( the LED will turn on) to place circuit in training mode, for word one, say the target word into the onboard microphone (near LED) clearly. The circuit signals acceptance of the voice input by blinking the LED off then on, the word (or utterance) is now identified as the " 01 " word. If the LED did not flash, start over by pressing " 1 " and then "TRAIN" key.

Continue training new words in the circuit. Press " 2 " then TRN to train the second word and so on. The circuit will accept and recognize up to 20 words (numbers 1 through 20). It is not necessary to train all word spaces. For the wheelchair 5 target words are sufficiently all you need to train. 
It is necessary repeating a trained word into the microphone. In recognition phase the number of the spoken word should be displayed on the digital display.

\section{Error Codes:}

The chip provides the following error codes.

$55=$ word to long

$66=$ word to short

$77=$ no match

\section{Clearing Memory}

To erase all trained words in memory press "99" and then "CLR". The numbers will quickly scroll by on the digital display as the memory is erased, trained words can easily be changed by overwriting the original word.

\section{Simulated Independent Recognition}

The speech recognition system in default is speaker dependant, meaning that the voice that trained the system has the highest recognition accuracy and limited to the spoken person. To make the recognition system simulates speaker independence, one uses more than one word space for each target word, now it can use many word spaces per target word for example, four words, therefore four different voice emission of each target word, the word spaces $01,11,21$ and 31 are allocated to the first target word. Continue do this for the remaining word space. For instance, the second target word will use the word spaces 02, 12, 22 and 32, and so on until all the words are programmed.

The first new idea of our project is enabling the system to recognize different voices, inflections and enunciations of the target word and robust the system resources that are allocated for independent recognition.

The second new idea of our project is after the completion of training our words it can ignore and cancel all electronic circuits connected to HM2007 like pad, 7-segments and their driver circuits leaving it to operate in standalone depending on the internal RAM of the PIC 18F458 microcontroller as shown in figure (4), these ideas leads to low cost, practically it needs to train once time at the manufacturing step, and drive the wheelchair by any customer's voice.

\section{c. Micro controller based circuit}

The microcontroller is the brain of the project and nothing can be done if it isn't fully functioning. It has the ability to send different signals to the DC Motors to reach the appropriate tasks.

The design demonstrates a Pulse Width Modulation PWM technique to control the speed of a DC motor. The motors are interfaced with PIC using $\mathrm{H}$-bridge driver circuit to control the motors movement and direction. 
PWM (Pulse Width Modulation) is a powerful technique for controlling analog devices like DC motors using digital signals. By controlling analog circuits digitally, system costs and power consumption can be greatly reduced. The duty cycle of a square wave is modulated to encode a specific analog signal level. The voltage or current source is supplied to the analog load by means of a repeating series of on and off pulses

$$
V_{\text {average }}=\text { Duty Cycle } * V_{\text {supply }}
$$

Speed and duty cycle are proportional to one another, for example, if a DC motor is rated to turn at $1500 \mathrm{RPM}$ at $12 \mathrm{~V}$, the motor will (ideally) turn at $750 \mathrm{RPM}$ when a 50\% duty cycle waveform is applied across the motor.

PWM is achieved in PIC microprogramming along timer-2 rather than in hardware and is controlled through external switch, there are three different motor speed levels: high speed ( $100 \%$ duty cycle), normal speed (50\% duty cycle), and low speed ( $25 \%$ duty cycle).

The frequency of the PWM waveform is an important consideration. Too low a frequency will result in a noisy motor at low speeds and sluggish response to changes in duty cycle. Too high a frequency lessens the efficiency of the system due to switching losses in the switching devices. A good rule of thumb is to modulate the input waveform at a frequency in the range of $4 \mathrm{kHz}$ to $20 \mathrm{kHz}$. This range is high enough that audible motor noise is attenuated and the switching losses present in the transistors are negligible. Generally, it is a good idea to experiment the PWM frequency for a given motor to find a satisfactory frequency.

Also, it needs some driving circuit, which generates high DC current to drive 12V 200 rpm motors with PWM digital frequency at $2^{11}=2048 \mathrm{~Hz}$.

Microcontroller output is drive by Darlington pairs of two bipolar transistors (either integrated or separated devices) connected in such a way that the current amplified by the first transistor is amplified further by the second one, the overall gain of Darlington Array: $\beta_{\text {darlington }}=\beta_{1} \cdot \beta_{2}$

\section{Phase 2 - Software Development Process}

The important step in this stage is to select an appropriate type of PIC microcontroller language for the programming, here it will use mikro C PRO for PIC which is the Advance C Compiler for PIC MCU provided by the Microelektronika company. Since the microcontroller is the PIC 18F458 microcontroller, the number of pin is limited, thus, the number of appliances that can be controlled are just a few but still sufficient. 


\section{WHEELCHAIR DESIGN PARTS}

The whole phases described previously can be briefed by the block diagram shown in figure (6).

\section{Block Descriptions ${ }^{[3,4,5]}$ :}

\section{a. Microphone}

The user will speak voice commands ("Right", "Left", "Forward", etc.) through the microphone which will pick up and use as an input. The microphone will be an electrets condenser, so it will need a voltage input of about 4 to $5 \mathrm{~V}$. The microphone itself contains a built-in field effect transistor amplifier stage, so the sound is amplified before it is sent to the voice IC for further amplification.

\section{b. Voice (IC)}

The voice IC will get the voice input from the microphone and perform the speech processing (training \&testing) as required, the HM2007 Speech Recognition chip is the basis of the Voice IC. For every command that has been trained into the chip, the corresponding output will be set high. Using the output, the correct action ("Right", "Left", "Forward", etc.) can be implemented.

\section{c. DC Power Source}

The main power supply to all parts of the wheelchair is a chargeable $12 \mathrm{~V}$ battery that is charged utilized an eight solar cell panel in addition to on- line charging.

The wheelchair electronic circuits can be powered by a few simple $5 \mathrm{~V}$, the voltage must be regulated to a safe value for each of the individual circuits and that will be handled by LM 7805 Voltage Regulator.

\section{d. Microcontroller (PIC 18F458)}

Our microcontroller will be essential for the integration of the rest of the system blocks. It will receive its inputs from the HM2007 voice IC and interpret the signals to direct the motors to follow its next instructions. It will be integral for the microcontroller to decide when to send the serial input to the motor driver, which serial signal to send, and which motor to move at what time in order to get the wheelchair to move in the correct direction and in a fluid motion.

\section{e. DC Motor}

The motion part contains two motors (right and left) with their drivers, the motors are DC types allowing the wheelchair to move forward, backward, turn right, and turn left. The motors will be synchronized so that the movement of each side will be one fluid motion. 
DC motors are very simple to use and control, which make them a short design-in item, generally two different styles of high torque DC motors: Brush Commutated and Gear Motor where the last one has high torque at load affects.

Bodine ${ }^{[6]} 12 \mathrm{v}$ DC gear motors are ideal for battery or solar powered applications, it offers a range of $12 \mathrm{v}$ permanent magnet DC (PMDC) gear motors up to $1 / 8 \mathrm{Hp}$, available with a variety of gearboxes, providing adjustable and wide speed range ( 8 to 660 RPM), low current requirement and hence low temperature, high starting torque ratings are up to $310 \mathrm{lb}$ ins and feature pulse width modulation (PWM) circuitry for precise speed control.

\section{f. Motor Driver Controller}

The purpose of a drive circuit is to give the controller a way to vary the current in the windings of the motor.

Bidirectional control of a DC motor requires a circuit called an H-bridge, named for its schematic appearance, is able to move current in either direction through the motor winding.

The Darlington H-bridge is the device that can be used to control all the motors by receiving a serial input signal from the microcontroller, it can interpret which motor to move and what PWM signals to send to it to rotate it to whatever position it needs to reach, also the current can be amplified to apply more torque to the DC motor and make it appropriate for high human weight.

It can add four diodes across the transistors to protect the transistors from current spikes generated by back EMF when the transistors are switched off.

Also it can add capacitors across the transistors. The value of these capacitors is generally in the $10 \mathrm{pF}$ range. The purpose of these capacitors is to reduce the RF radiation that is produced by the arching of the commutators.

\section{g. Liquid Crystal Display (LCD)}

In this project, the LCD is mainly function for the display of the current command executed to ensure that the user knows what command and which devices is currently in active mode to ease the user to monitor and a better controlling on the system. The choice of the LCD used here is the LM 016L. Figure (7) shows the overall system operation flow chart

\section{ACCURACY OF RECOGNITION ANALYSIS:}

Various tests were performed on the completed speech recognition circuit to investigate its robustness and to characterize performance. The first set of tests looked at the recognition accuracy which is the most important parameter in any speech recognition system because it tests the whole system from start to end. In some extreme cases the system can 
become unusable or even dangerous when the recognition accuracy percentage drops too low. In a study of speech recognition in high-performance fighter aircraft where speech recognition was used for controlling flight displays, setting radio frequencies, and weapon release parameters it was determined that a high recognition accuracy (correct classification above $95 \%$ ) was the most critical factor in making the system useful.

The device has been trained with several words. Each word is stored on several location numbers. Table (1) shows the location number and word that has been train respectively.

Figure (8) shows the accuracy of the device respond to the words for ten speakers of the noiseless speech.

The result is based on 10 set of trials for each word and accuracy is based on whether it gives the correct output or it gives other value. Error codes are not counted because it means that the word has not been pronounced correctly.

Figure (8) shows that some word doesn't give the correct respond especially when the words trained have a similarity between the words, thus to turn off one appliance, other appliance might be turned off unintentionally; this is because the system is independent voice recognition. The body of tone changes which include syllable, morpheme and words within a flow of speech constitute the intonation. Intonation displays variations according to the level of education, social level and the present psychological state of the speaker and the speech environment. That's why it is very difficult to establish definite patterns and rules for intonation.

Figure (9) shows the accuracy of the device respond to the words for ten speakers of noisy speech with SNR of $30 \mathrm{~dB}$, which are most similar to that of noiseless speech.

Figure (10) shows the accuracy of the device respond to the words for ten speakers of noisy speech with SNR of $20 \mathrm{~dB}$.

Figure (11) shows the accuracy of the device respond to the words for ten speakers of noisy speech with SNR of $10 \mathrm{~dB}$.

It shows that when the device is used in a noisy environment, the accuracy of the device will reduce to half from the expected result where interference from the noise affects the device recognition very much. Even when a command was not given to the device, with the present of random talk, the device still continues detecting to capture the sound wave.

As noise increased, the device is confused between the words "forward", and "backward" because those two words have a similarity in the end of their Pronunciations. The second set of tests is the similar words pronunciation test, Figures (12) and (13) show the 
result of experimenting between the two words (right, write) and (left, lift) that has approximately similar pronunciation. The test is done 12 times for each word.

It results in clearly the efficiency of our system is very good where the Pronunciation of the words "right" and "write" is very approach, while the Pronunciation of the words "left" and "lift" is of large difference.

\section{CONCLUSION:}

Speech technology has become widely accepted and is now being used expensively in industrial control, service, and programmable fields due to easiest producing of speech.

It can summarize the system feature as follow:

Works for both males and females and for most types of accents.

$>$ Works in a natural environment (with some background noise), so it is suitable for both clean and telephony voice.

$>$ Programming the microcontroller in C-language rather than other languages leads to easy and best simulation programs.

$>$ Gear DC motors are very simple to use and control, which makes them a short design-in item. PIC microcontrollers, especially those with CCP or ECCP modules are ideally suited for driving DC motors through using the PWM.

Future work can include:

$>$ Expand to operate with Arabic phenomena speech.

$>$ It can utilizing the DWT (Discrete Wavelet Transform) in both feature extraction and speech de-noising.

$>$ It can use the Neural Networks as classification technique with efficient results, but Neural Networks needs to large processing time due to updating the weight of its layers, so this method is not suitable to wheelchair for large words which needs to speed process rather than accuracy.

$>$ It can use special classification techniques with efficient results like SVM, KNN.

$>$ It can combine many speaker recognition techniques like HMM and GMM to speed up learning and obtaining best results.

$>$ Though the speed of a DC motor is generally proportional to duty cycle, no motor is ideal. Heat, commutator wear and load all affect the speed of a motor. In systems where precise speed control is required, it is a good idea to include some sort of feedback mechanism in the system, where speed feedback is implemented in one of two ways: The first involves the use of a speed sensor of some kind. The second uses the BEMF voltage generated by the motor. 


\section{RERERENCES}

1. Vinit D Patel, "Voice Recognition System in Noisy Environment", California state university, Sacramento, 2011.

2. Choy Meng Onn, "Voice Recognition Home Automation System”, Universiti Teknologi Malaysia, 2010.

3. Hossein Ghaffari Nik, "Hum-Power Controller for Powered Wheelchairs", George Mason University, 2009.

4. Musa Hakan ASYALI1, Mustafa YILMAZ2, Mahmut TOKMAKC3, Kanber SEDEF4, Bekir Hakan AKSEBZEC5, Rohin MITTAL6, "Design and Implementation of a VoiceControlled Prosthetic Hand", Turk J Elec Eng \& Comp Sci, Vol.19, No.1, 2011, c_ T"UB'ITAK.

5. Raciel Poot, Victor Chi, Lizzie Narváez, Erika Llanes, Maximiliano Canché, "Design and Construction of a Prototype of an Electronic Wheelchair Drive for People with Motor Disabilities", IJCSNS International Journal of Computer Science and Network Security, VOL.10 No.7, July 2010.

6. www.bodine-electric.com | info@bodine-electric.com

Table (1): location number and word that has been train respectively.

\begin{tabular}{|c|c|c|}
\hline Location No. & Train Word & Description \\
\hline 01 & Right & Right motor on, Left motor off \\
\hline 02 & Left & Right motor off, Left motor on \\
\hline 03 & Forward & Both motors on forwardly \\
\hline 04 & Backward & Both motors on in back direction \\
\hline 05 or 08 & Stop & Both motors off \\
\hline
\end{tabular}




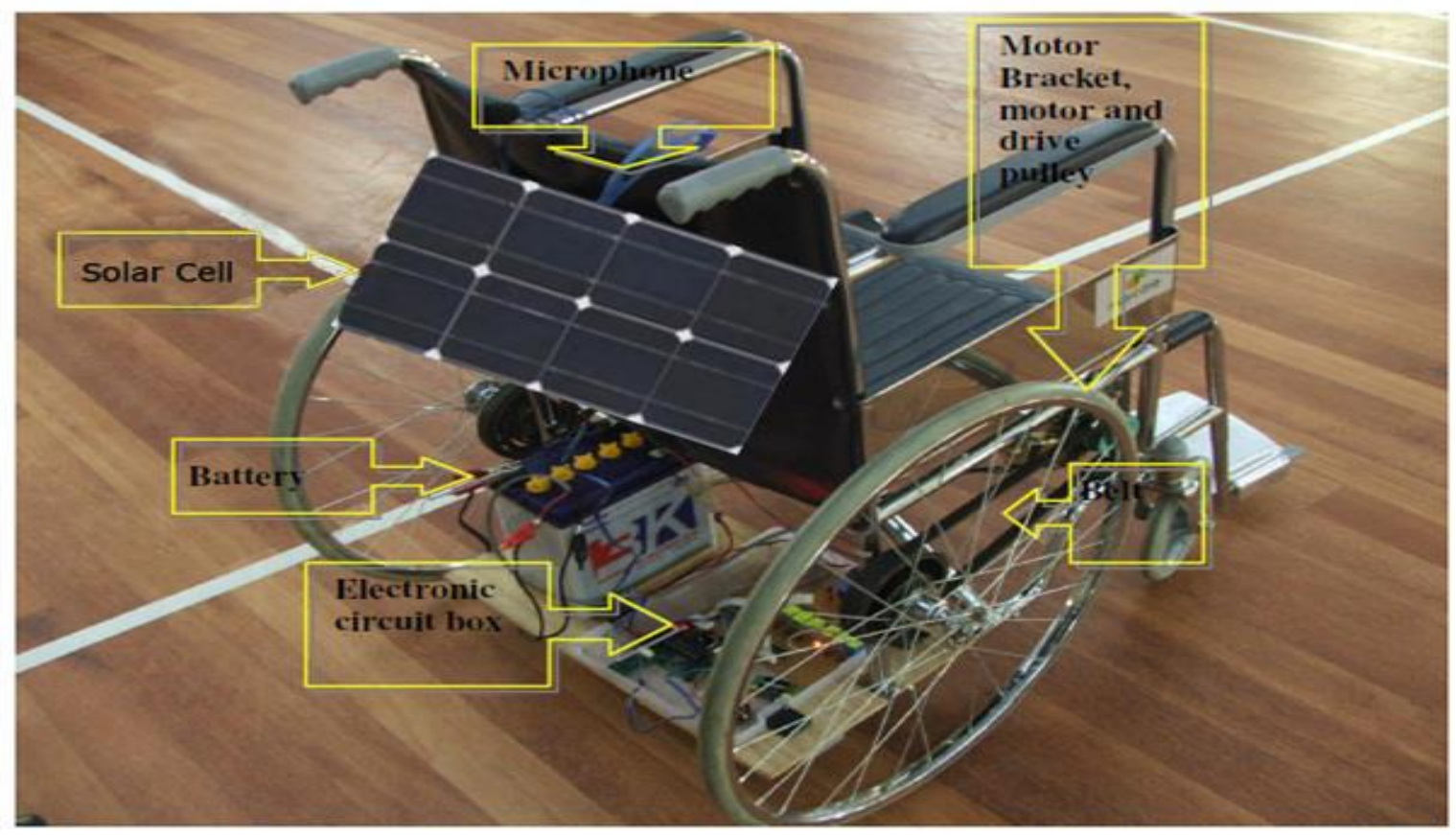

Fig (1): the completed voice controlled wheelchair.

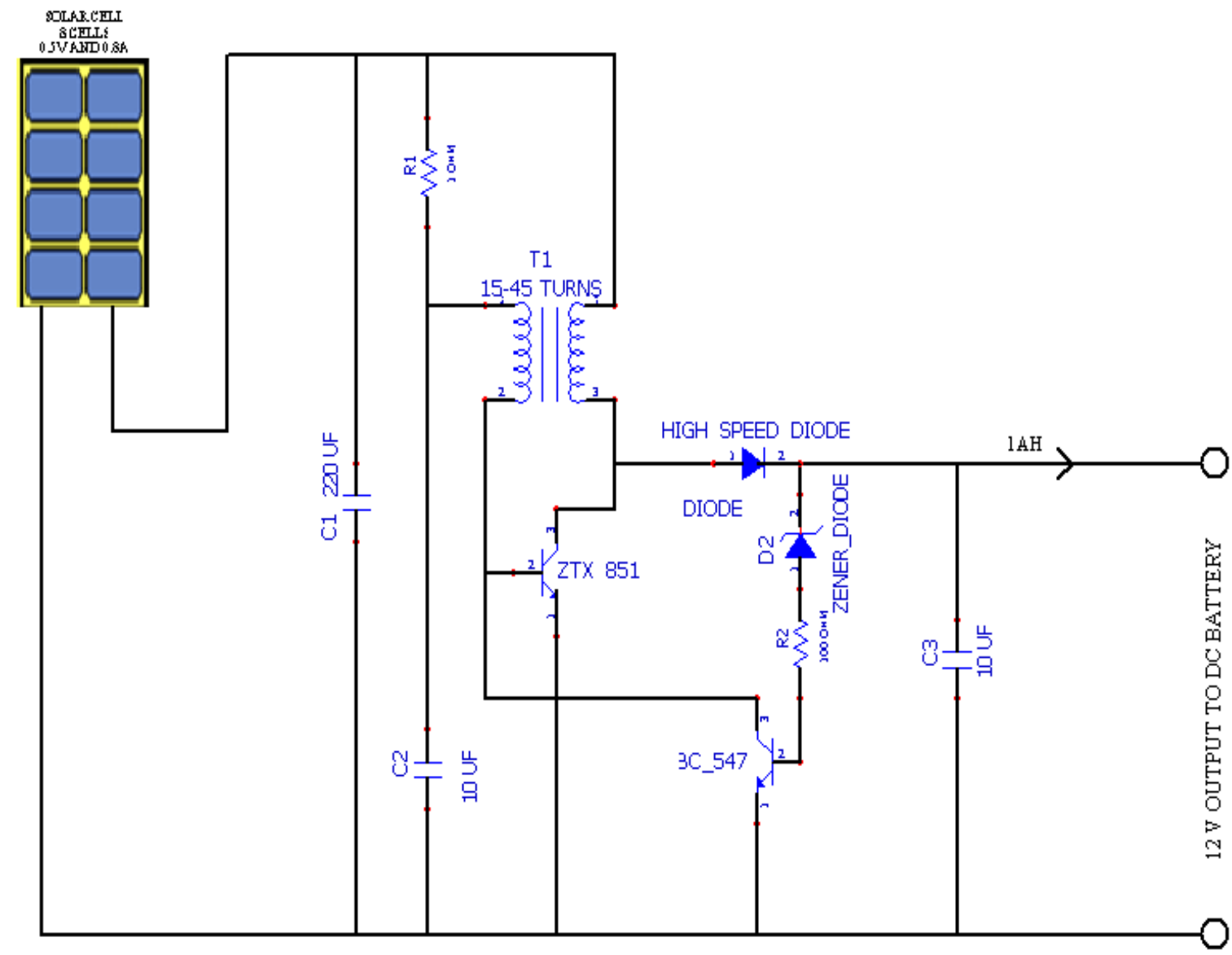

Fig (2): solar cell charger circuit. 


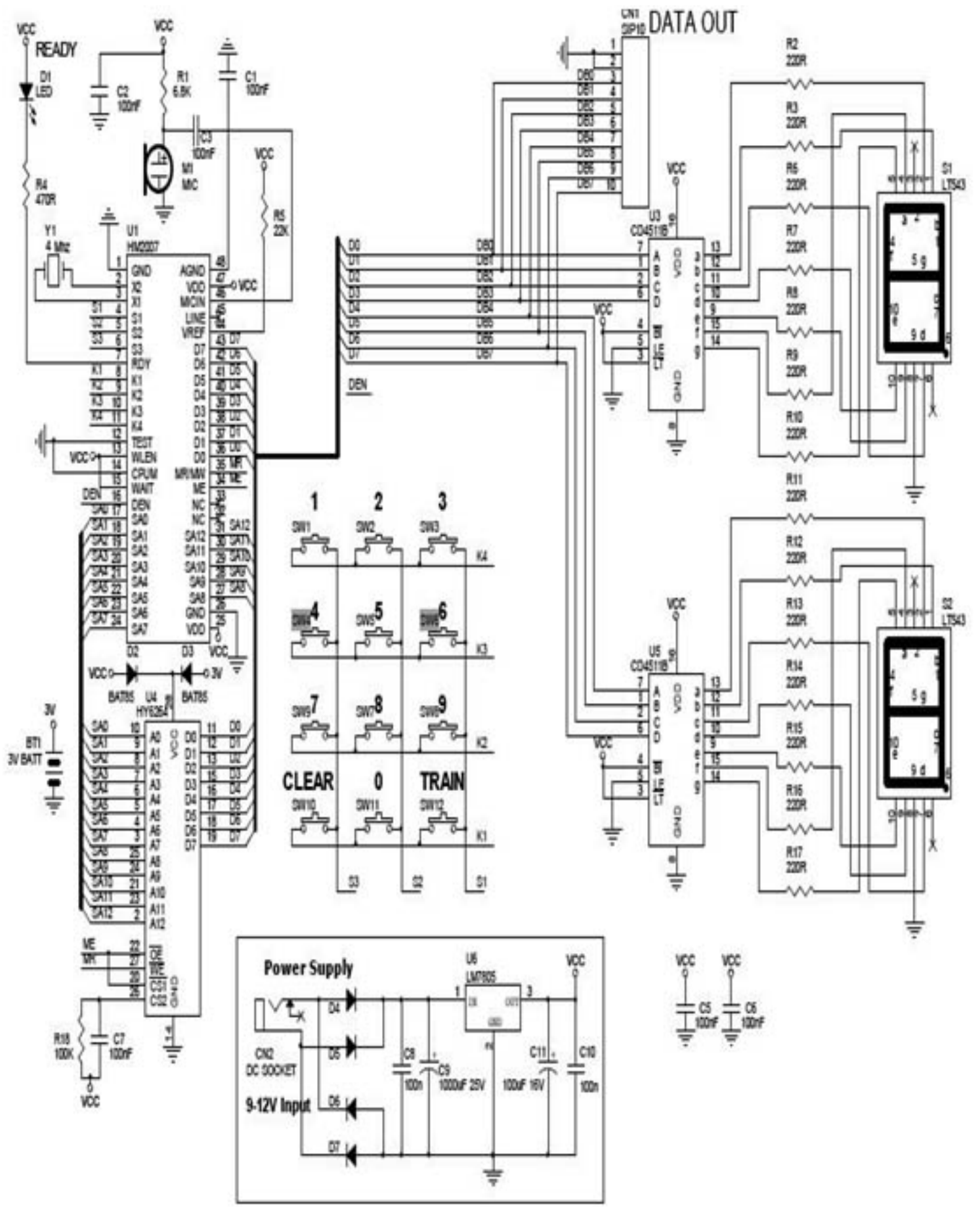

Fig (3): HM2007 speech recognition system. 


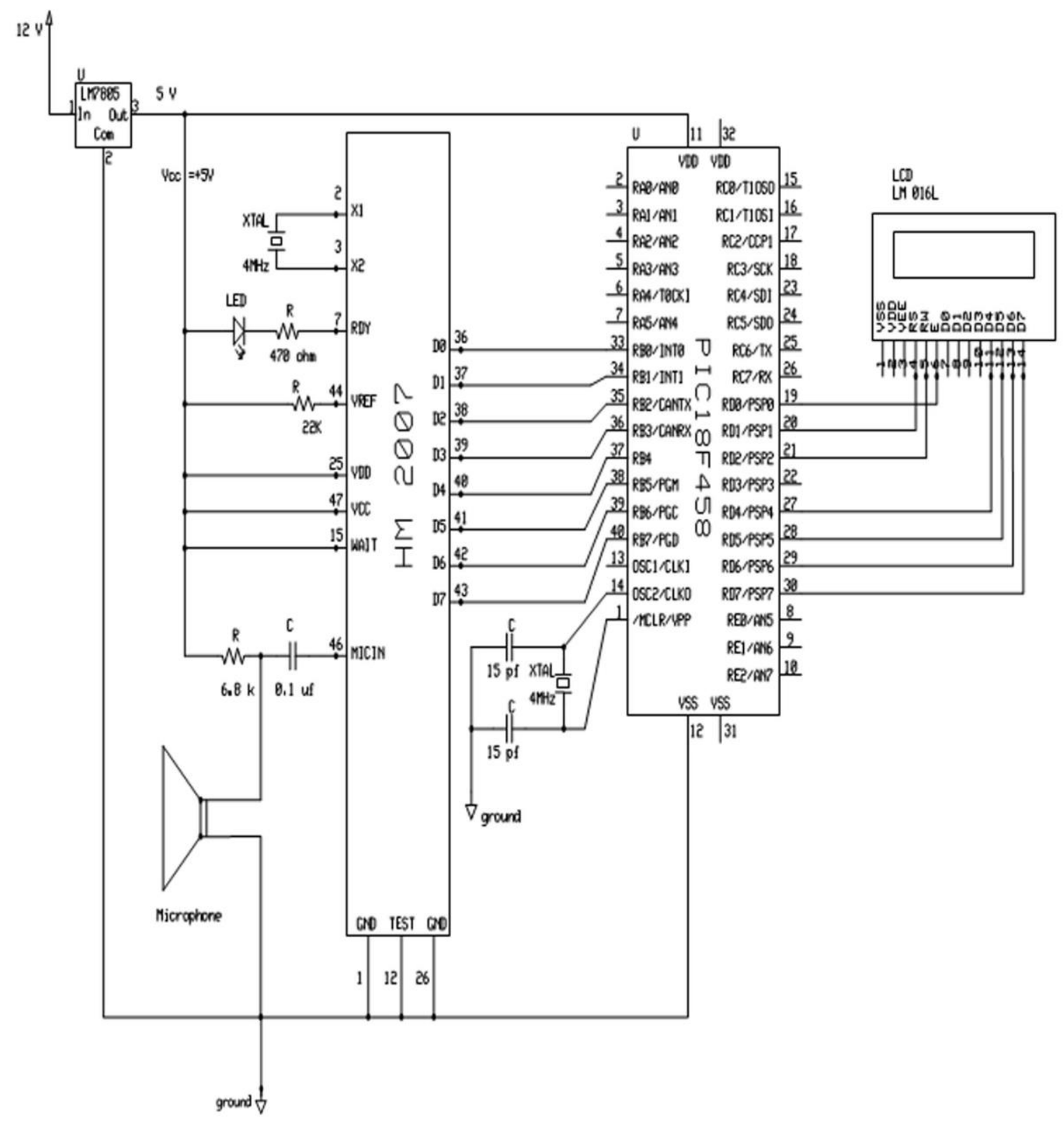

Fig (4): standalone HM2007 with Microcontroller. 


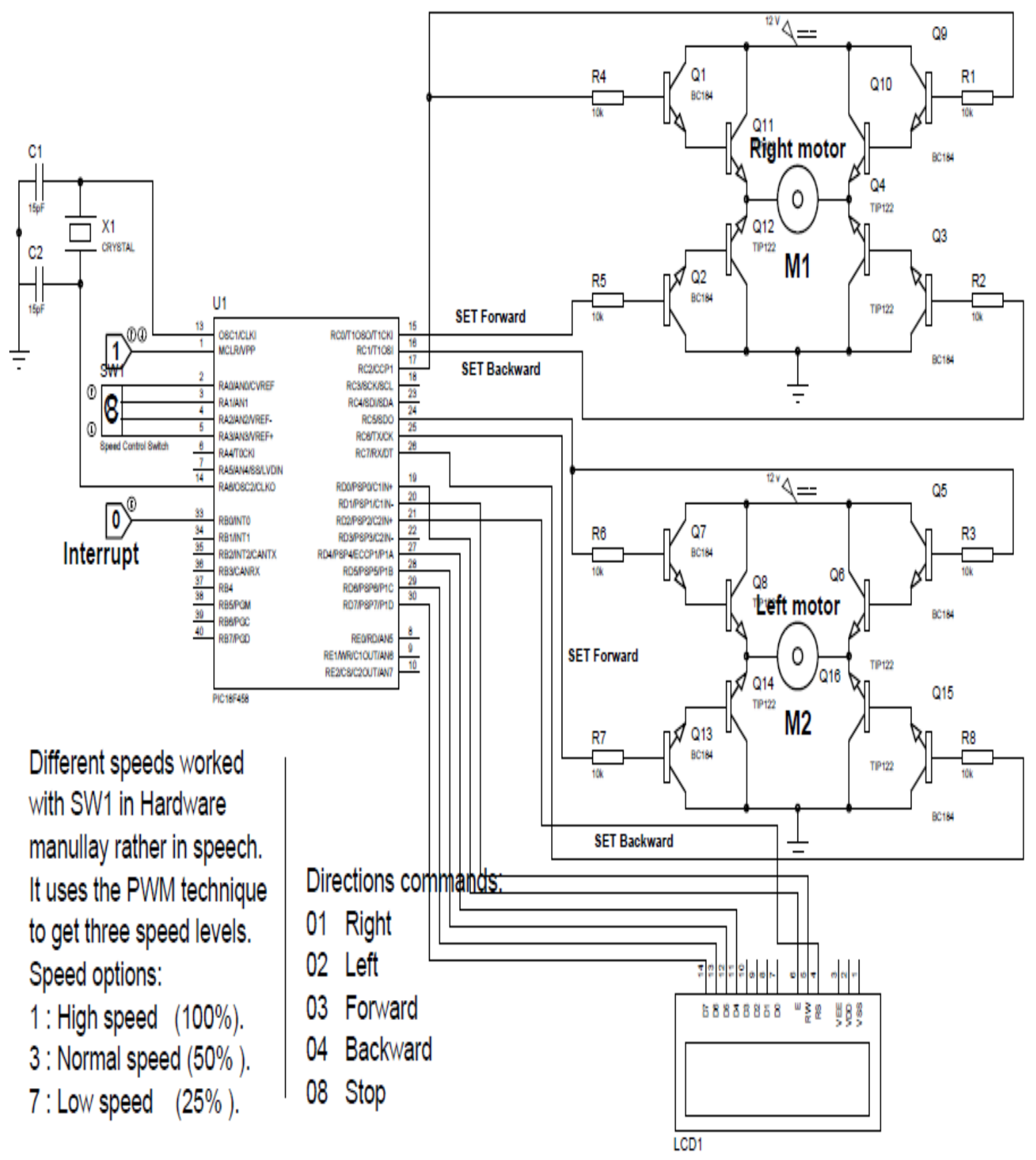

Fig (5): Wheelchair motor with H-driver circuit. 


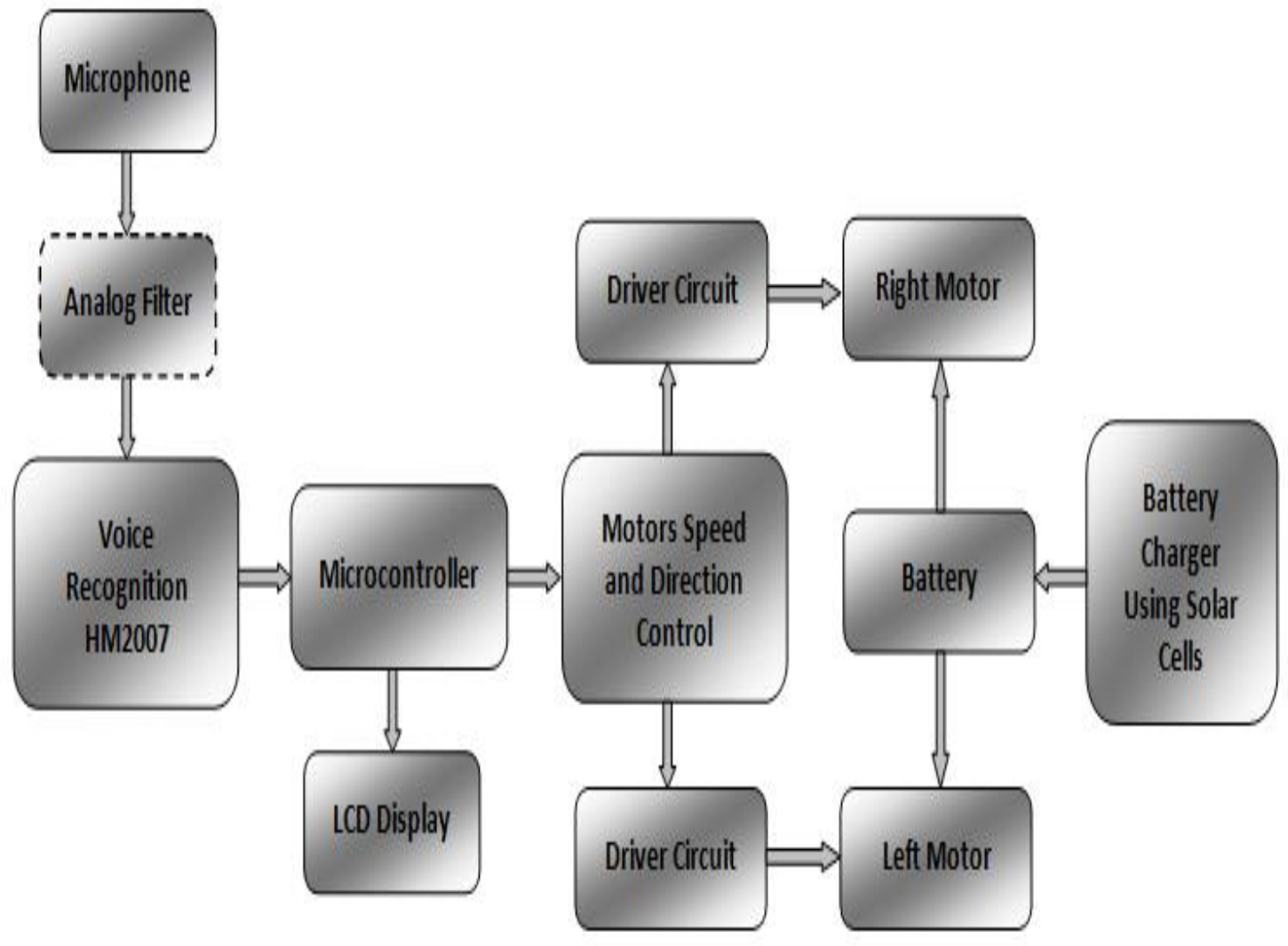

Fig (6): overall hardware block diagram 


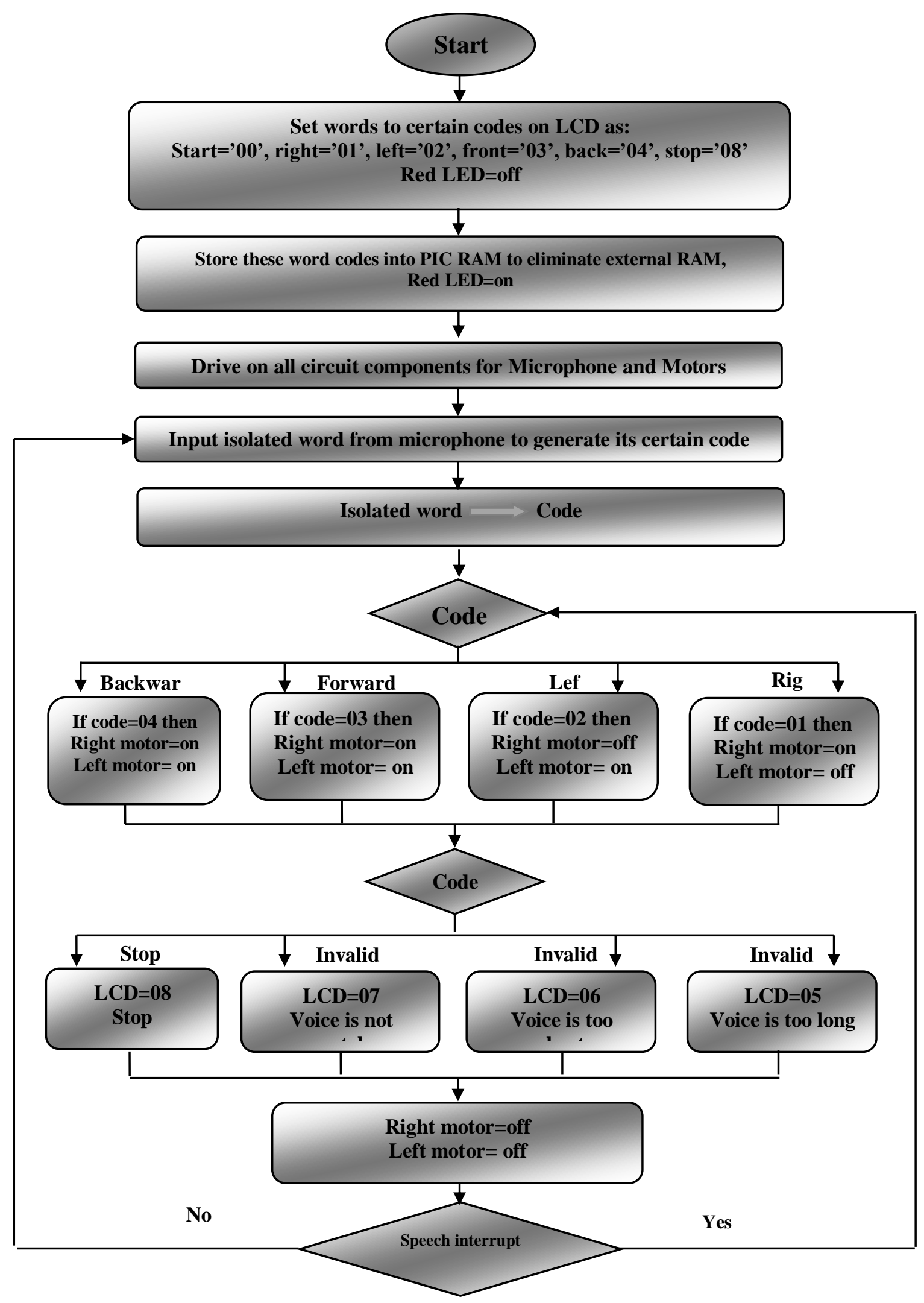

Fig (7): system flow chart of operation. 


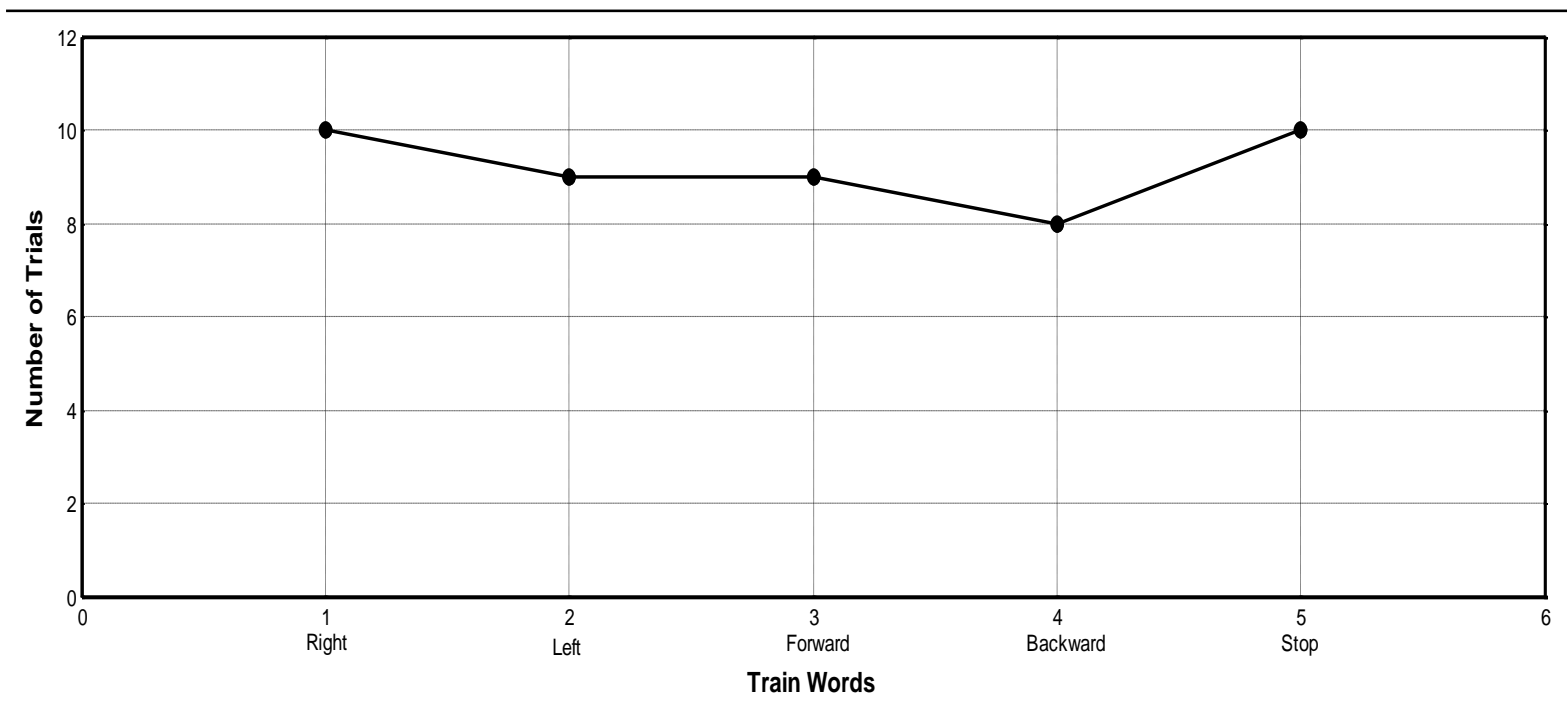

Fig (8): Device accuracy response at noiseless

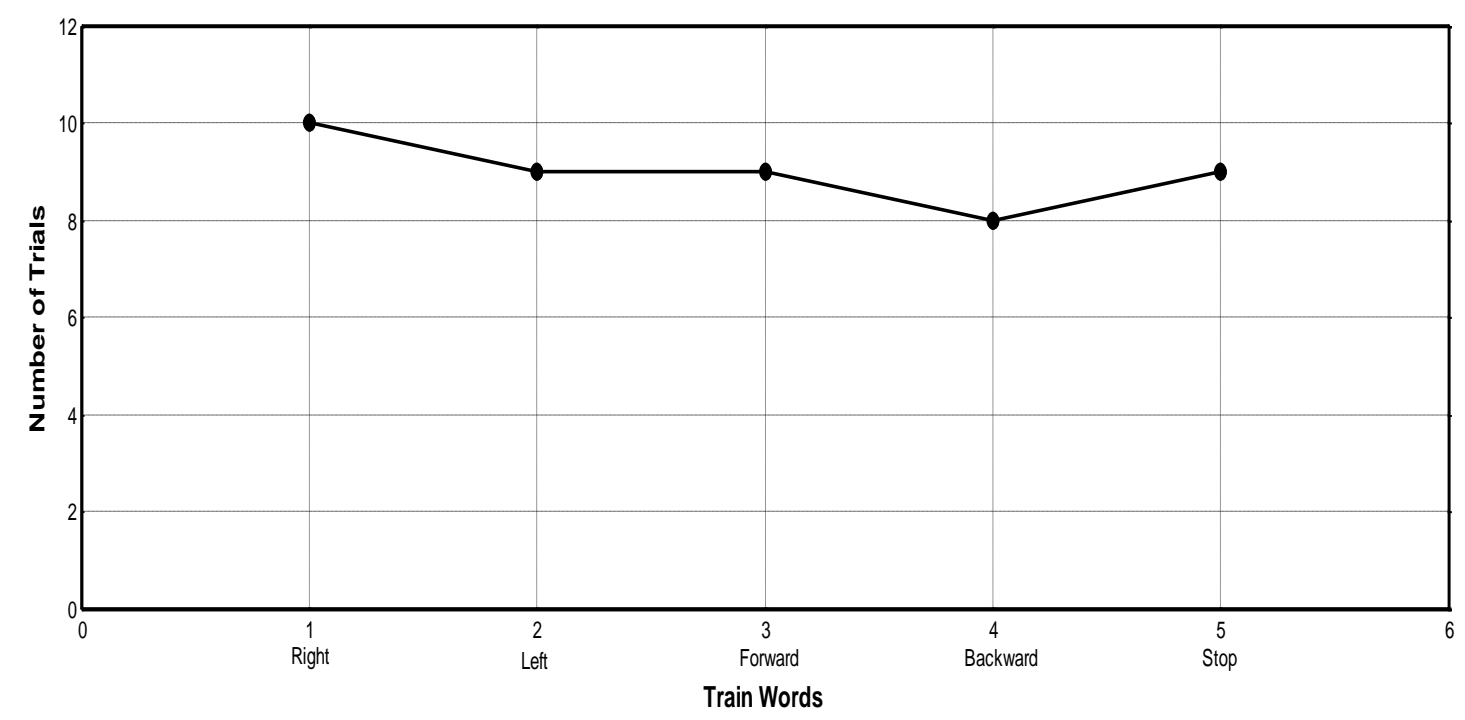

Fig (9): Device accuracy response at $\mathrm{SNR}=30 \mathrm{~dB}$

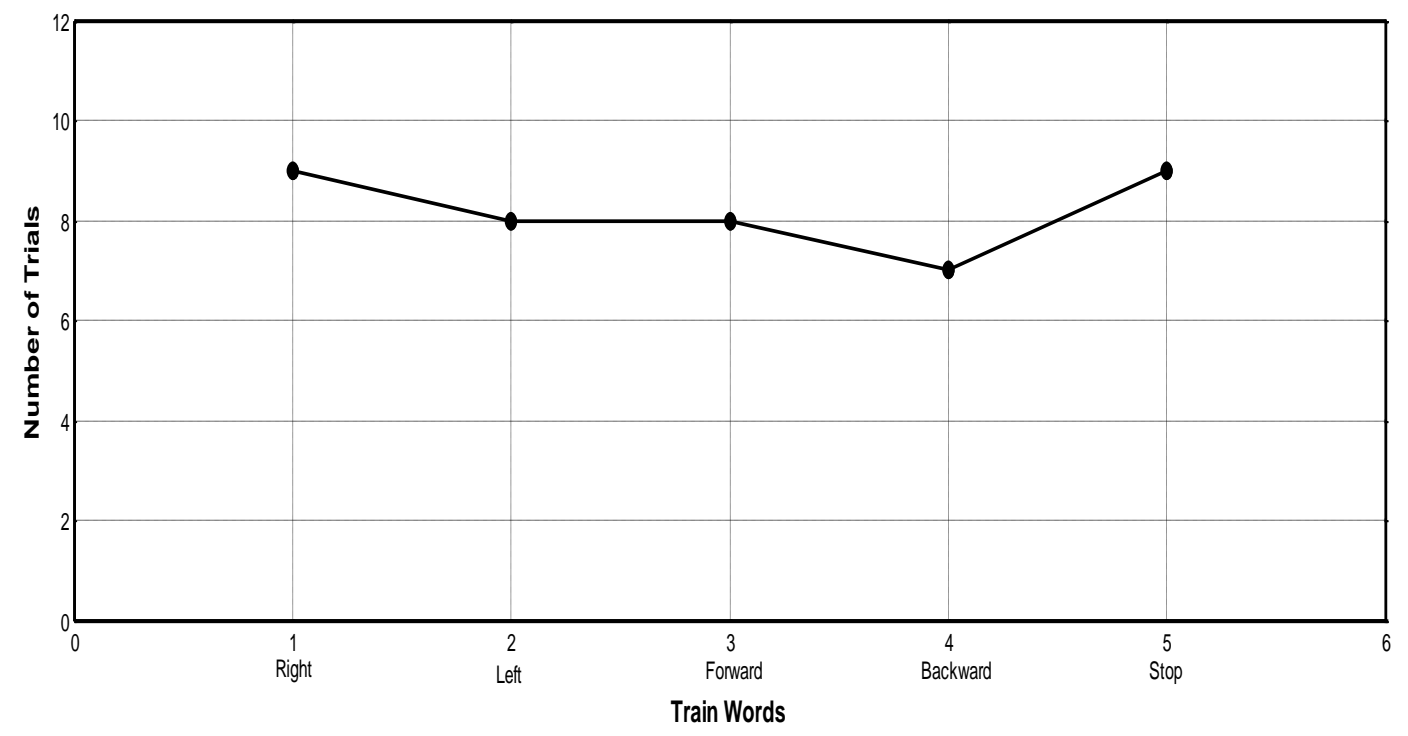

Fig (10): Device accuracy response at $\mathrm{SNR}=20 \mathrm{Db}$. 


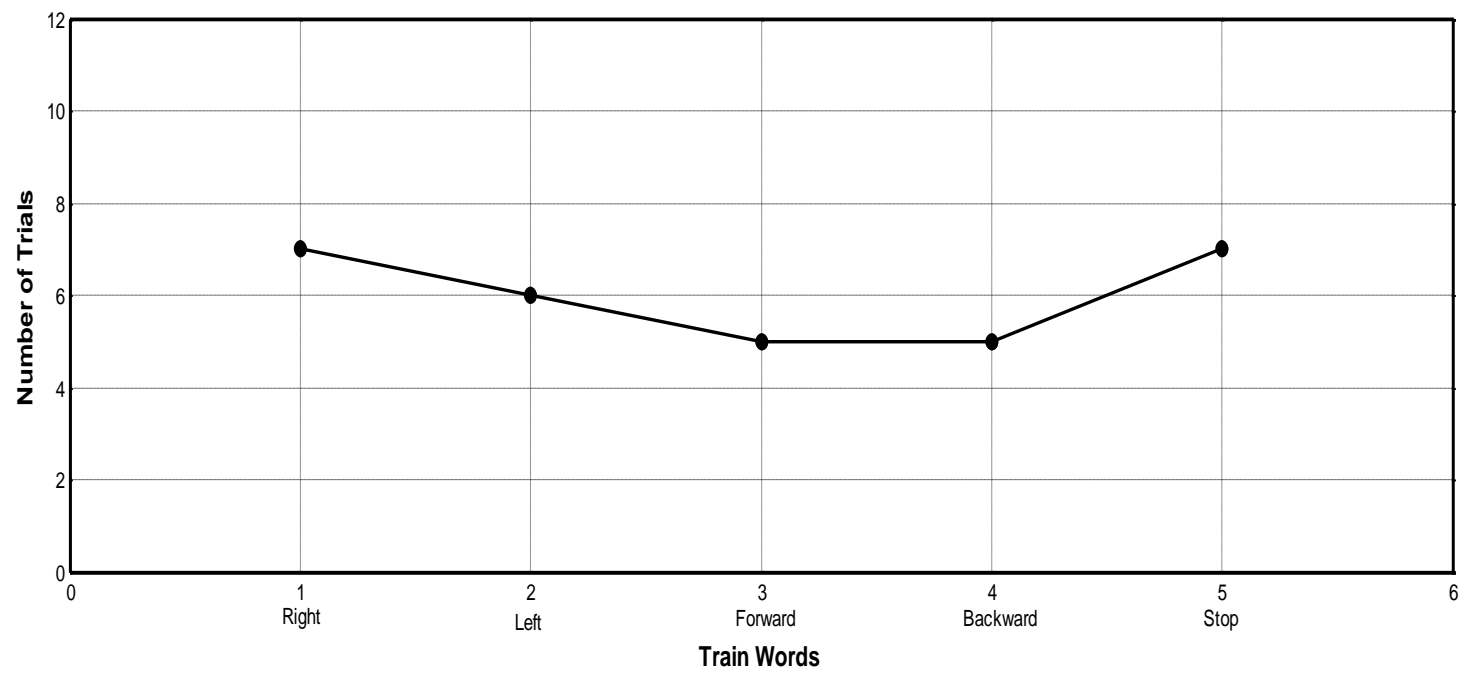

Fig (11): Device accuracy response at $\mathrm{SNR}=10 \mathrm{~dB}$.

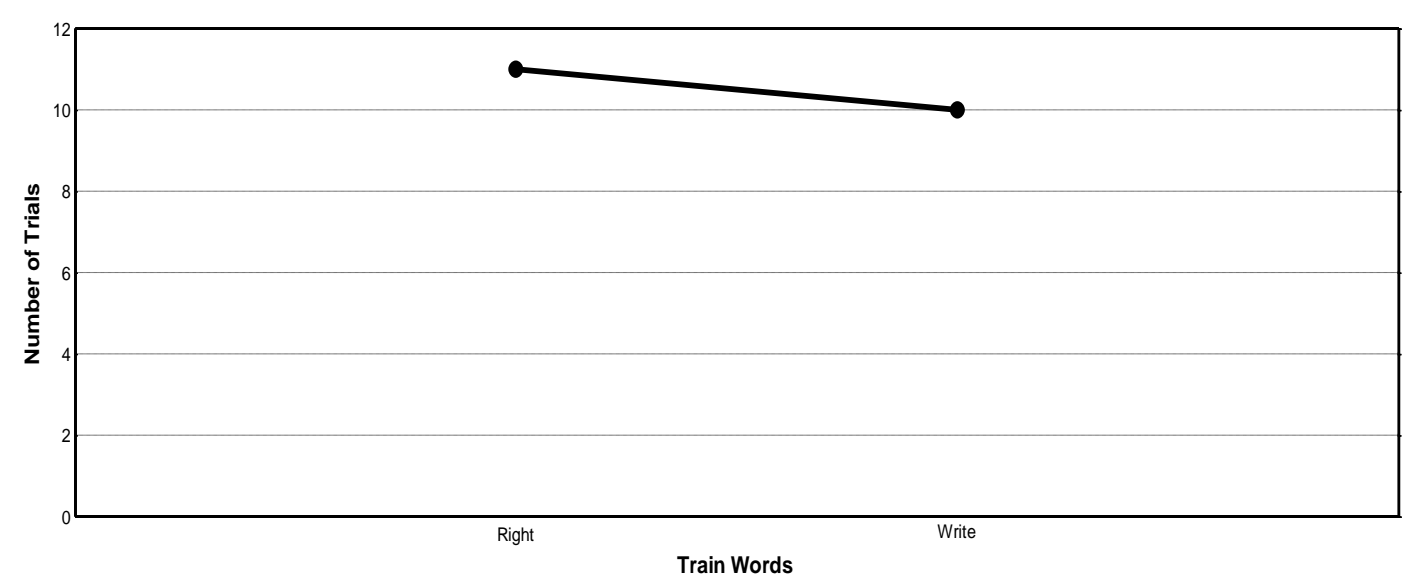

Figure (12): Pronunciation Experiment Result.

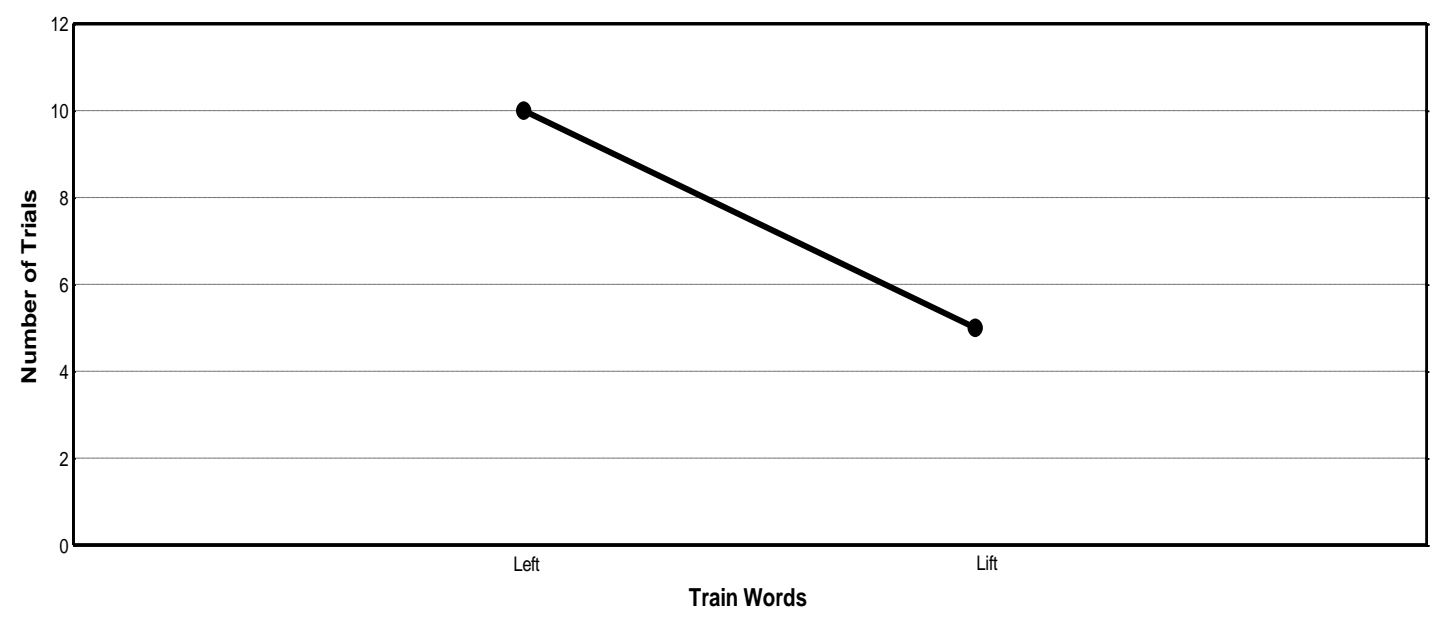

Figure (13): Pronunciation Experiment Result. 


\title{
تصميم، نمذجة و تنفيذ كرسي كهربائي متحرك بالاعتماد على ال PIC
}

\author{
مهند عبد شهاب احمد \\ مدرس، كلية الهندسة، الجامعة المستتصرية
}

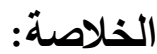

في الوقت الحاضر ، يعتبر الصوت احد الطرق المستخدمة للسيطرة على الأجهزة الكهربائية والإلكترونية بسبب

سهولة نوليده من قبل الإنسان. كثير من المعاقين ليس لديهم المهارة اللازمة للسيطرة على عصا التحكم في الكرسي التئي الكهربائي المتحرك. الهذف من هذه الدراسة هو تتفيذ كرسي متحرك باستخدام نظام التحكم في الخدمات الصوتية والسيطرة على المحركات في الكرسي المتحرك. يعتبر ال بمثابة الأذن التي تستمع وتفسر الأمر الصوتي في حين أن IC HM2007 بمثنابة

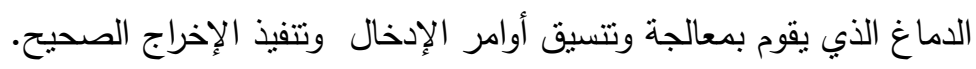

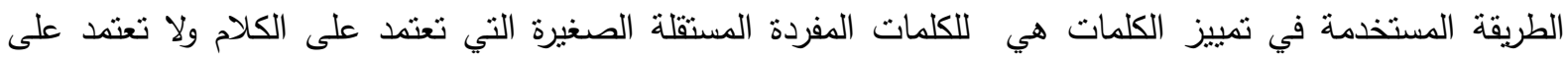
المتكلم حيث نحتاج لجملتين الأولى للتنديب والثانية للاختبار . مدخلات النظام عبارة عن مجموعة من خمس كلمات تستخدم للسيطرة على اثثين من المحركات المربوطة لل PIC 18F458 الذي يستخدم كجهاز للبرمجة والتحكم، يتم ضبط سرعة المحركات باستخدام تقنية PWM (نبض تعديل العرض) حيث تتتوع دورة العمل للوقت حسب السرعة المطلوبة. لزيادة كفاءة المنظومة نم تصميم واختبار المنظومة بنجاح في بيئة مختلفة ونسب قوة إثارة متغيرة إلى نسب الضوضاء,

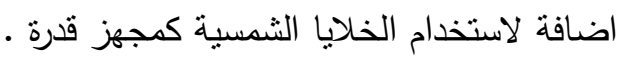
وأخيراً، تم اختبار دوائر النظام المقترح بناءا" على قاعدة بيانات من عشرة متكلمين فقط (6 من الذكور و 4 من الإناث)

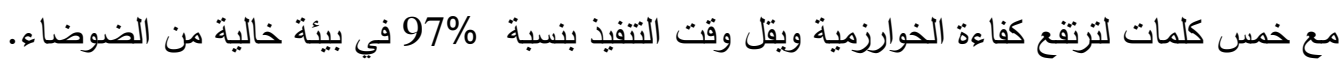
الكلمة الاليلية : HM2007، الخلايا الثمسية، دائرة دارلينكتون، PIC 18F458، كرسي متحرك ، تمييز الكلام، برمجة فئه مايكرو C. 